\title{
(过)
}

\section{A INFLUÊNCIA DA TEMPERATURA DE PRÉ-AQUECIMENTO EM JUNTA SOLDADA PELO PROCESSO TIG EM AÇO ASTM A335 P11}

\section{THE INFLUENCE OF PREHEATING TEMPERATURE IN JOINT WELDED BY TIG STEEL ASTM A335 P11}

\author{
Orlando Fortunato Pereira ${ }^{\mathrm{I}}$ \\ Péricles Bosquetti ${ }^{\mathrm{II}}$ \\ Maria Aparecida Bovério ${ }^{\text {III }}$
}

\begin{abstract}
RESUMO
O aço ligado ASTM A335 P11 pode apresentar diferentes comportamentos ao sofrer diferentes tratamentos térmicos. O objetivo do presente trabalho foi de analisar comparativamente juntas soldadas do aço ASTM A-335 grau P11, unidas pelo método de soldagem TIG, em temperatura ambiente e realizando-se um pré-aquecimento de $200^{\circ} \mathrm{C}$ antes da soldagem. O metal base utilizado foi o aço ASTM A335 P11 e o metal de adição utilizado foi a vareta de solda ER $80 \mathrm{~S}-\mathrm{B} 2$. Foram realizados ensaios metalográficos, medidas de microdureza e ensaios de tração. Observou-se que não houve mudança significativa na microestrutura do material base nem na zona termicamente afetada tanto para o material base sem pré-aquecido quanto para o material pré-aquecido à temperatura de $200^{\circ} \mathrm{C}$. Entretanto, na região do metal de solda observou-se uma microestrutura pouco mais irregular no metal que foi pré-aquecido, além de ter sido observado um leve aumento de dureza na região soldada nas amostras com o pré-aquecimento à $200^{\circ} \mathrm{C}$. Conclui-se que o pré-aquecimento à $200^{\circ} \mathrm{C}$ utilizado neste trabalho influiu discretamente na microestrutura, dureza e consequentemente nas propriedades mecânicas da junta soldada do metal base ASTM A335 P11.
\end{abstract}

Palavras-chave: ASTM A335 P11. Pré-aquecimento. Soldagem TIG.

\begin{abstract}
ASTM A335 P11 alloy steel can have several tempers when undergoing a heat treatment. The objective of the present work was to comparatively analyze the welded joints of steel ASTM A-335 grade P11, joined by the TIG welding method, with ambient temperatures and preheating of $200^{\circ} \mathrm{C}$. The base metal used for steel ASTM A335 P11 and the metal used for addition to the rod ER 80S-B2. Metallography, microhardness, and tensile tests were carried out. It was observed that there was no reduction in the microstructure of the base material nor

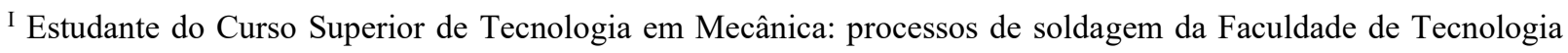
Deputado Waldyr Alceu Trigo de Sertãozinho (Fatec-Stz) - São Paulo - Brasil. E-mail: orlandopereira_stz@hotmail.com

II Prof. Dr. da Faculdade de Tecnologia Deputado Waldyr Alceu Trigo de Sertãozinho (Fatec-Stz) - São Paulo Brasil. E-mail:pericles.bosquetti@fatec.sp.gov.br

III Pós-Doutorado em Educação (UNESP-Rio Claro), Doutorado, Mestrado e Especialização em Educação pesquisadora da Faculdade de Tecnologia (Fatec) - Câmpus de Sertãozinho e Jaboticabal. Membro do Grupo de Estudos e Pesquisas em Políticas e Gestão da Educação Superior (GEPES) do Departamento de Educação da UNESP, Câmpus de Rio Claro, vinculado ao CNPq. E-mail: maria.boverio@fatec.sp.gov.br
} (UNESP-Araraquara), Bacharel em Letras (Centro Universitário Moura Lacerda-Ribeirão Preto). Docente e
\end{abstract}




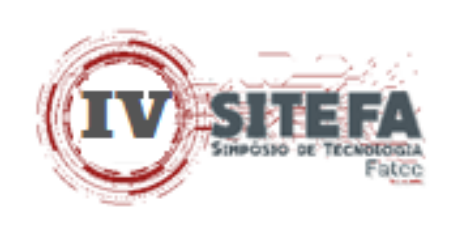

in the thermally affected zone for both the non-preheated base material and the base material preheated to a temperature of $200^{\circ} \mathrm{C}$, however, for the weld metal there was no more irregular microstructure without preheated metal. There was an increase in hardness with the help of preheating to $200^{\circ} \mathrm{C}$. It is concluded that preheating to $200^{\circ} \mathrm{C}$ directly influences the microstructure, hardness, and tensile strength of the ASTM A335 P11 metal base welded joint.

Keywords: ASTM A335 P11. Pre-heating. TIG welding.

Data de submissão do artigo: 30/06/2021.

Data de aprovação do artigo: 23/07/2021.

DOI: $10.33635 /$ sitefa.v4i1.178

\section{INTRODUÇÃO}

Devido ao surgimento de novos materiais e desenvolvimento de novas técnicas durante a recente revolução industrial, houve grande avanço nas indústrias, que passaram a ampliar a empregabilidade de materiais metálicos com as mais diversas especificações. Neste processo, com o intuito de minimizar problemas devido às divergências nos lotes de materiais, os fabricantes passaram a criar e divulgar essas especificidades necessárias dos materiais que utilizam, mediante a emissão de descrições detalhadas dos mesmos, a fim de que, quem empregasse-os respeitassem tais normas de qualidade (ASTM, 2016).

No caso dos aços, passou a serem solicitados testes mecânicos simples para determinar alguns parâmetros como a resistência à tração e elasticidade do material. Atualmente, a indústria americana, através da criação dos comitês de normas como a ASTM (American Society Testing and Materials), internacionalizou e padronizou a maioria dos testes. Após anos de aprendizado na indústria americana, a ASTM internacionalizou os processos e hoje apresenta um dos maiores sistemas de padronização de materiais e testes do mundo (ASTM, 2016).

Um aço amplamente utilizado nas indústrias termelétricas é o ASTM A-335 classe P11, devido seu excelente desempenho à altas temperaturas e suas mais variadas respostas aos diferentes tipos de tratamentos térmicos (BOSQUETTI et al., 2015). A soldagem desses aços precisa de atenção especial, uma vez que são materiais temperáveis devido a adição de elementos de liga, e apresentam as zonas termicamente afetadas sujeitas ao endurecimento (GIMENES JUNIOR, 1997).

A maior parte dos metais são excelentes condutores térmicos, de maneira que, o calor gerado na região da solda escoa de maneira rápida por toda a massa do metal, resultando em um rápido resfriamento. Dessa forma, tem-se que para as várias regiões do aço há diferentes taxas de resfriamento crítico e caso haja um excedente do calor crítico no metal de solda, pode ocorrer a formação de estruturas endurecidas de martensita que podem resultar em fraturas e quebras devido as influências das tensões térmicas geradas (PEREZ, 2007).

Um método amplamente empregado para eliminar as trincas induzidas após o resfriamento do metal no processo de soldagem é o pré-aquecimento, pois, ele reduz a taxa de resfriamento da solda, além de minimizar as chances de formação de microestruturas frágeis, intervindo nas propriedades mecânicas da junta que sofreu a soldagem (GASPAR, 2013).

O objetivo do presente trabalho foi de analisar comparativamente juntas soldadas do aço ASTM A-335 grau P11, unidas pelo método de soldagem TIG, realizando-se a soldagem com os materiais em temperatura ambiente e realizando-se o pré-aquecimento à $200^{\circ} \mathrm{C}$, 


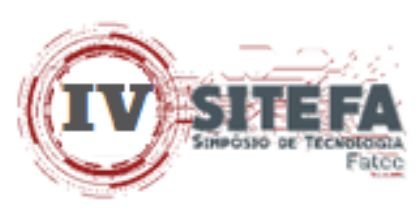

verificando-se assim, a influência do pré-aquecimento na microestrutura e nas propriedades mecânicas na região soldada.

\section{PROCESSO DE SOLDAGEM}

O processo de soldagem consiste na união de peças, ou seja, a junção do metal de base (peça que está sendo soldada) com o metal de adição que ocorre na poça de fusão dando origem ao cordão da solda. Dessa forma, após o processo de soldagem, formam-se as zonas da junta soldada, que são divididas em três regiões principais afetadas pelo calor, sendo: a zona fundida (ZF), que é composta pelo metal de adição; a zona termicamente afetada (ZTA) que é a região do metal de base que apresenta estrutura e/ou suas propriedades alteradas pelo calor de soldagem; e o metal de base (MB), que compõe a peça propriamente dita (MARQUES; MODENESI; BRACARENSE, 2011).

$\mathrm{O}$ ideal seria que o metal de solda apresentasse as mesmas características e propriedades que o da zona afetada pelo calor ou que o material de base. Entretanto, isso não ocorre, uma vez que a maioria dos materiais de base provém do estado de forja ou de laminação e o metal de solda é fundido. A microestrutura formada na zona fundida terá influência de fatores como: da presença e concentração de elementos de liga, composição química e distribuição de tamanho de inclusões não-metálicas, microestrutura de solidificação, tamanho do grão da austenita anterior e ciclo térmico de soldagem. Desta forma, pode-se afirmar que ocorrerão mudanças de características mecânicas do metal na ZTA, que por sua vez poderão não resistir a alguns fatores externos em que a peça será submetida e em que o material base foi projetado (FORTES, 2005; WAINER; BRANDI; MELLO, 2011).

São diversos os processos de soldagem, que por sua vez podem ser divididos de acordo com o tipo de fonte de energia utilizada, o tipo de proteção e a natureza de união. Quanto ao tipo de fonte de energia utilizada tem-se a mecânica, a química, a elétrica e a radiante (WAINER; BRANDI; MELLO, 2011).

Já, quanto aos tipos de proteção têm-se a vácuo, a gás inerte, a gás e a fluxo. Cabe ressaltar que existem alguns processos de soldagem que não empregam nenhum tipo de proteção como são os casos da: soldagem por explosão, por atrito, por ultrassom, por ponto etc. Enquanto, o processo de soldagem por natureza de união envolve dois grandes grupos, sendo: a soldagem por pressão ou por deformação e soldagem por fusão (WAINER; BRANDI; MELLO, 2011).

Dentro do processo de soldagem por natureza de união no grupo do processo de fusão, destacam-se por sua empregabilidade nas indústrias os seguintes: Flux-Cored Arc Welding (FCAW), Gas Metal Arc Welding (GMAW), Gas Tungsten Arc Welding (GTAW), Plasma Arc Welding (PAW), Submerged Arc Welding (SAW) e Shielded Metal Arc Welding (SMAW) (MARQUES; MODENESI; BRACARENSE, 2011).

\subsection{Soldagem a arco com eletrodo de tungstênio ou Gas Tungsten Arc Welding (GTAW) ou Tungsten Inert Gas (TIG)}

O processo de solda a arco com eletrodo de tungstênio de proteção gasosa, do inglês Gas Tungsten Arc Welding (GTAW), também conhecido como Tungsten Inert Gas (TIG), visa a união de peças metálicas resultante do aquecimento e fusão destas por meio de um arco elétrico estabelecido entre a peça e um eletrodo de tungstênio não consumível. Com intuito de 


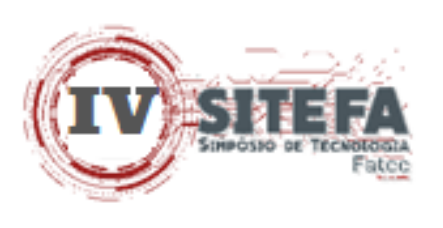

proteger o eletrodo e a poça de fusão da oxidação e contaminações atmosférica, a poça de fusão e o arco são protegidos por um fluxo ou nuvem de gás inerte ou mistura de gases inertes, que ao serem ionizados, proporcionam a condução da corrente elétrica (CIRINO, 2009; MARQUES; MODENESI; BRACARENSE, 2011).

Os gases normalmente empregados são Argônio e Hélio, que também podem ser misturados e, em outros casos, a mistura de gases com Hidrogênio e Nitrogênio podem também ser empregadas. Esse tipo de soldagem pode ou não ser realizada com metal de adição, que se utilizado, ocorre diretamente na poça de fusão (CIRINO, 2009; MARQUES; MODENESI; BRACARENSE, 2011).

São utilizados como equipamentos básicos no processo de soldagem TIG a fonte de energia, a unidade de alta frequência, o reservatório de gás e a tocha TIG (WAINER; BRANDI; MELLO, 2011). Dessa forma, a fonte de soldagem a ser usada deve ser analisada, tendo como opções a corrente contínua de polaridade direta, a corrente contínua de polaridade inversa e a corrente alternada, na qual cada uma destas apresentam suas próprias características e peculiaridades (OKUMURA; TANIGUCHI, 1982).

No caso de correntes referentemente baixas há uma emissão termiônica, que é o fenômeno de emissão de elétrons quando um metal é aquecido, e precisa-se de uma maior tensão para empurrar um número suficientes de elétrons para a corrente pretendida, assim, sua mancha catódica possui uma temperatura relativamente baixa (CAMPBEL; La COURSIERE, 1995). Conforme a corrente é aumentada, há um aumento do cátodo, que contribui na facilitação de emissão termiônica, e há um aumento, de maneira progressiva, no grau de ionização da região de queda catódica e da coluna do arco. Dessa forma, tem-se uma maior superfície emissiva, há também um condutor elétrico mais vigoroso, facilitando a circulação da corrente, uma tendência à diminuição da tensão (CAMPBEL; La COURSIERE, 1995).

Para a corrente contínua de polaridade direta, tem-se que os elétrons vão do eletrodo para o metal base, proporcionando uma penetração bem profunda, uma vez que a junta de solda será eletricamente bombardeada. Já para corrente contínua de polaridade inversa, na junta soldada há uma penetração menos profunda, o que pode resultar em problemas de ligamento (OKUMURA; TANIGUCHI, 1982).

Esse tipo de soldagem não é aplicado em juntas espessas, em função da pequena taxa de deposição que ele resulta $(0,2$ a até $2 \mathrm{~kg} / \mathrm{h})$. Contudo, há necessita de alta qualidade, juntas de grandes espessuras podem ser soldadas completamente ou somente o passe raiz realizado por soldagem TIG (MACHADO, 1996).

\subsection{Aço-liga ASTM A-335 grau P11}

Dentre os principais tubos de condução de aço-liga, encontra-se o ASTM A-335, que é caracterizado como um tubo de aço ligado ferrítico, não apresentam costura, e são voltados para atividades de temperatura elevadas. Eles devem atender as normas internacionais ASTM A-335 e possuem graus/classes P5, P9, P11, P22, P91 e P92, são recomendados para o uso em caldeiras de alta pressão (TUBOS ABC, 2019).

O material A-335 é uma classificação de materiais da ASTM específica para tubos de aço-liga e baixa liga, para serviços de alta pressão e alta temperatura (até $590^{\circ} \mathrm{C}$ ) e as classes P5 e P9 são indicadas para processos de refinaria, enquanto as classes P11, P22, P91 e P92 são para indústrias energéticas (TUBOS ABC, 2019).

Apesar do aço A-335 classe P11 apresentar propriedades mecânicas inferiores aos demais, ele apresenta baixo coeficiente de expansão térmica e alta condutividade térmica. 


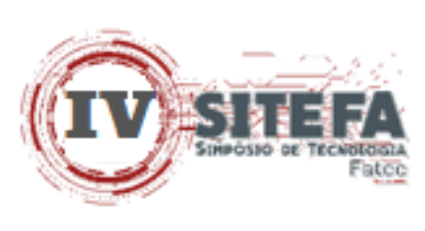

Torna-se a melhor alternativa dentro dos ciclos térmicos, equipamentos e componentes a vapor pressurizado, além de possuir um custo menor que os demais (ASTM, 2015).

O aço-liga ASTM A-335 P11 apresenta em sua composição 1,0\% de cromo e 0,5\% de molibdênio. É um material empregado em tubulações de indústrias químicas, estações de geração de energia, tubos superaquecidos, caldeiras, trocadores de calor e vasos de pressão devido desempenho à elevadas temperaturas (FONSECA, 2004; ZAMPIERI JÚNIOR, 2014).

\subsection{Tratamento térmico e o pré-aquecimento}

Normalmente, são realizados dois tipos de tratamentos térmicos em soldas de tubulações, sendo elas: o pré-aquecimento e o pós-soldagens. O objetivo do pré-aquecimento é de diminuir a taxa de resfriamento ao término da solda, fazendo com que o material não resfrie rapidamente, o que resultaria no endurecimento excessivo devido possível formação de fase martensítica, de ductilidade baixa (TELLES, 2001).

O tratamento térmico pode ser executado de maneira localizada, por aquecimento de uma banda circunferencial ao longo de todo componente da solda identificada ao centro aproximado da banda (ASME, 2016).

O pré-aquecimento em metais que possuem elevada condutibilidade térmica promove as operações de soldagem de maneira mais fácil (GIMENES JUNIOR, 1997). É definido como temperatura de pré-aquecimento a temperatura inicial na qual as peças, ou parte dela, será exposta antes do processo de soldagem iniciar-se. Dessa forma, tem-se que diferentes tipos de soldagens podem exigir diferentes tipos de temperaturas (PEREZ, 2007; MARQUES; MODENESI; BRACARENSE, 2011).

Tem-se ainda que o pré-aquecimento da junta onde será realizado o processo de solda, pode reduzir a taxa de resfriamento do metal. Assim, tem-se que a temperatura de préaquecimento, dependendo do tipo de solda e do tipo de material pode estar no intervalo de 50$540^{\circ} \mathrm{C}$, contudo, normalmente utiliza-se um intervalo de $150-200^{\circ} \mathrm{C}$ (PEREZ,2007). Um adequado controle do pré-aquecimento nas regiões adjacentes a junta a ser soldada é essencial, para que ocorra a retirada de umidade da peça (GASPAR, 2013).

O processo de pré-aquecimento pode diminuir o teor de martensita da solda, refinar os microconstituintes produzindo grãos mais uniformes, desta forma, proporcionando a melhoria da ductilidade, redução da dureza e diminuindo a probabilidade de ocorrência de fissuras ao decorrer do resfriamento. Em alguns metais o rápido resfriamento da estrutura pode favorecer no surgimento de microestruturas no local da solda que podem ser benéficas ao processo de soldagem e união das estruturas evitando trincas após sua soldagem (FORTES, 2005; ROSALINO; SFALSIN JUNIOR; SIQUEIRA, 2014).

\section{MATERIAIS E PROCEDIMENTOS METODOLÓGICOS UTILIZADOS}

O metal base utilizado foi uma chapa do aço ASTM A335 P11, com espessura de 9,75 $\mathrm{mm}$ e $6000 \mathrm{~mm}$ de comprimento para soldagem das amostras, cuja faixa de composição química está apresentada na Tabela 1. O metal de adição utilizado foi a vareta ER 80S-B2, com diâmetro de 1/8", que é indicada para soldagem de aços resistentes a fluência, como o AS-387 grau 11 e o ASTM A335 P11. 


\section{(IV) SHTEA}

Tabela 1 - Composição química do aço ASTM A335 Grau P11

\begin{tabular}{cccccccc}
\hline Grau & C & Mn & P $\leq$ & $\mathbf{S} \leq$ & Si & Cr & Mo \\
\hline P11 & $0.05-0.15$ & $0.30-0.60$ & 0.025 & 0.025 & $0.50-1.00$ & $1.00-1.50$ & $0.44-0.65$ \\
\hline
\end{tabular}

Fonte: ASTM (2015)

A Figura 1 mostra as chapas chanfradas preparadas com ângulo de $37,5^{\circ}$ :

Figura 1 - Chapas chanfradas usadas para a realização das soldagens

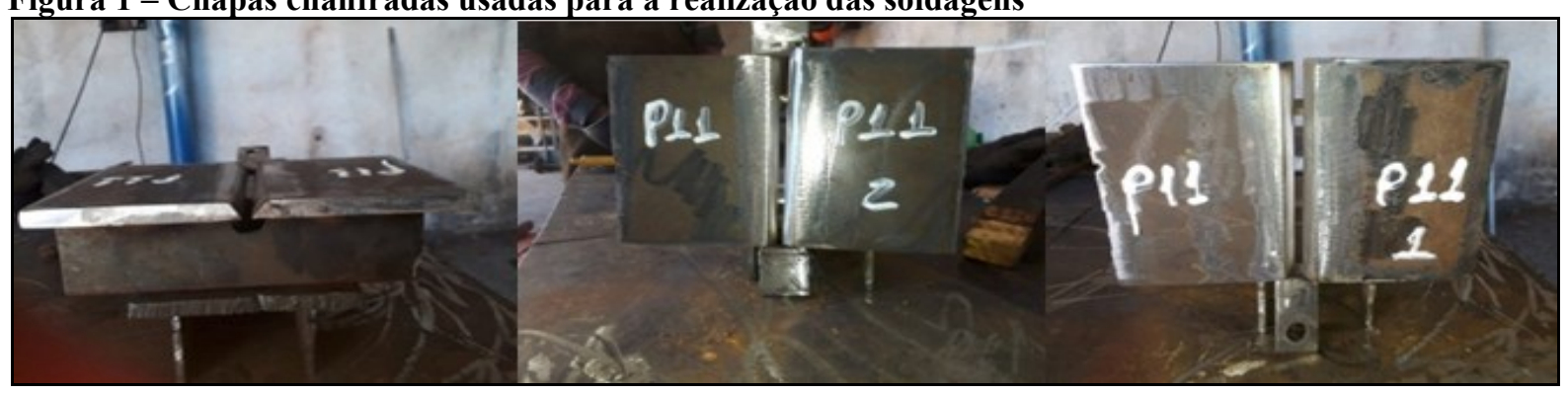

Fonte: os autores (2021)

Para a realização das soldagens, duas chapas foram mantidas à temperatura ambiente enquanto as outras duas foram pré-aquecidas à temperatura de $200^{\circ} \mathrm{C}$. Para acompanhamento da temperatura de pré-aquecimento, foi utilizado termômetro digital MINIPA MT350A.

O aquecimento das chapas foi realizado com o auxílio de um conjunto de oxiacetileno, com pressões de oxigênio de $3,0 \mathrm{kgf} / \mathrm{cm}^{2}$ e do acetileno de $0,5 \mathrm{kgf} / \mathrm{cm}^{2}$, dois reguladores de gás, duas mangueiras, um punho com o misturador de gases e o bico $\mathrm{n}^{\circ} 10$.

Para a soldagem, foi utilizada uma inversora de solda ESAB Tipo LHN 220i Plus

Após a soldagem, utilizando uma fresadora universal TOS $n^{\circ} 3$, foram confeccionados corpos de provas para ensaios de tração com medidas conforme a norma ASTN E8/8M-11. Também foram confeccionadas tiras com medidas de 10x10x210 mm para a realização dos ensaios de metalografia e microdureza.

\subsection{Ensaios de Tração}

Para realização dos ensaios de tração foi utilizada a máquina de ensaios mecânicos universal da marca INSTRON da Fatec Sertãozinho.

\subsection{Ensaios de Metalografia}

Para a metalografia, as amostras foram preparadas em Politriz Metalográfica Marca Teclago, Modelo PL 02 EDT. Fez-se o polimento progressivo utilizando-se as lixas 120, 220, $320,400,600,800$ e 1000 e em seguida, fez-se os polimentos em politriz utilizando-se pano para polir e pó de alumina de 1 micron, revelando-se na sequência através de ataque químico por Nital 2\%. O microscópio utilizado para análise de metalografia (microestrutura) foi o Microscópio Óptico, Marca ZEISS Modelo Áxio Vert. A1, na Fatec Campus Sertãozinho SP. 


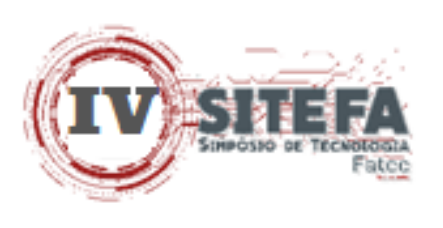

\subsection{Ensaios de Microdureza}

Para as microdurezas, utilizou-se microdurômetro digital Modelo MHV 2000, Marca TIME utilizando as mesmas amostras dos ensaios de metalografia, na Fatec Sertãozinho SP.

\section{RESULTADOS E DISCUSSÕES}

Os resultados obtidos referente aos ensaios de metalografia, de microdureza e de tração, comparando os comportamentos do material base (chapa de ASTM A335 P11) préaquecida à $200^{\circ} \mathrm{C}$ e material base (chapa ASTM A335 P11) não aquecida estão a seguir.

\subsection{Ensaios de Metalografia}

Pode-se observar na Figura 7 a distribuição da microestrutura do metal base (ASTM A335 P11), analisado por meio de metalografia com aumento de 200 vezes. Na Figura 7A encontra-se o metal que não sofreu pré-aquecimento, enquanto a Figura $7 \mathrm{~B}$ refere-se ao material pré-aquecido a $200^{\circ} \mathrm{C}$.

Nota-se que não houve mudança significativa na microestrutura do material base, tanto para o material base sem pré-aquecimento quanto o material base pré-aquecido à temperatura de $200^{\circ} \mathrm{C}$, o que era de se esperar, visto sem uma temperatura baixa para alterações na microestrutura. Ao analisar-se as Figuras (7A e 7B) nota-se a ocorrência de ferrita (partes claras) e perlita (partes escuras), em grãos refinados, típicos do aço P11 recozido.

Figura 7 - Metal base, ataque Nital 3\% em aumento 200x. (A) material base sem pré-aquecido e (B) material base pré-aquecido à $200^{\circ} \mathrm{C}$

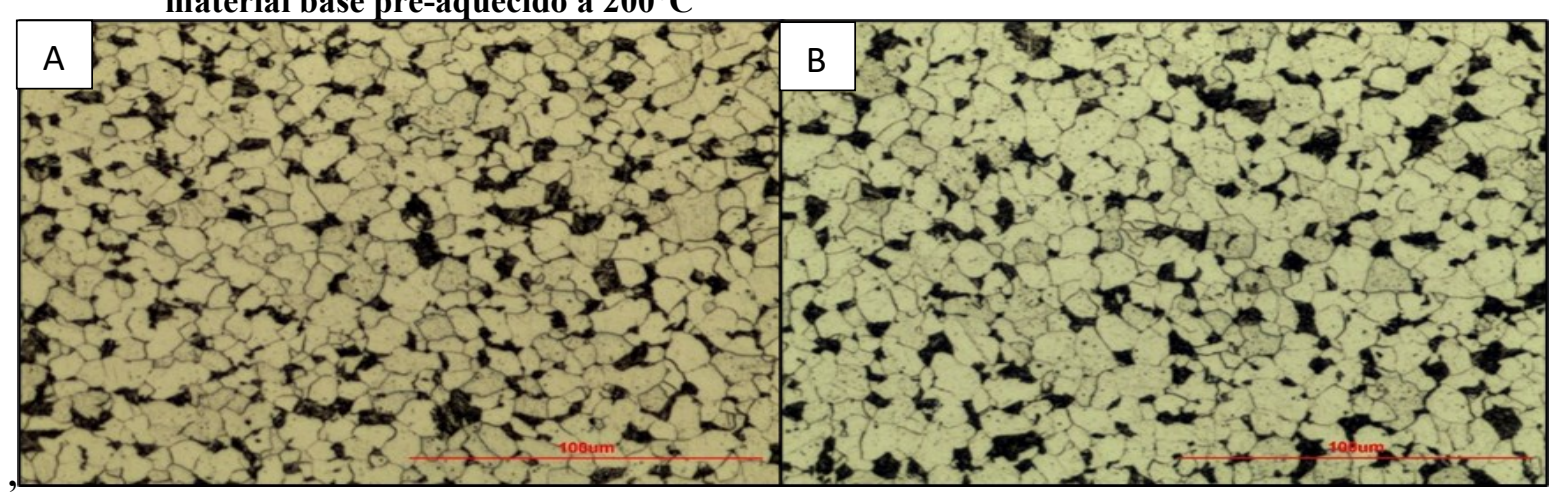

Fonte: os autores (2021)

Na Figura 8 é apresentado a região de transição entre o metal base e a zona termicamente afetada (ZTA) pela soldagem. Tanto na Figura 8A (metal base não préaquecido) como na $8 \mathrm{~B}$ (material base pré-aquecido à $200^{\circ} \mathrm{C}$ ), observa-se uma diminuição do tamanho dos grãos da microestrutura do aço ASTM A335 P11. A zona afetada termicamente (ZTA) apresentou-se com microestrutura constítuida de grãos ferríticos e perlíticos menores e mais refinados, possivelmente isto ocorreu ao aquecimento acima da zona crítica e devido ao posterior resfriamento, mais rápido, gerado durante a soldagem TIG, ocasionou a formação de grãos mais refinados, em ambas as microestruturas. 


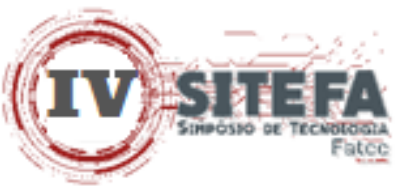

Figura 8 - Metal base e ZTA ataque Nital 3\% em aumento 100x. (A) Material base não pré-aquecido e (B) Material base pré-aquecido à $200^{\circ} \mathrm{C}$

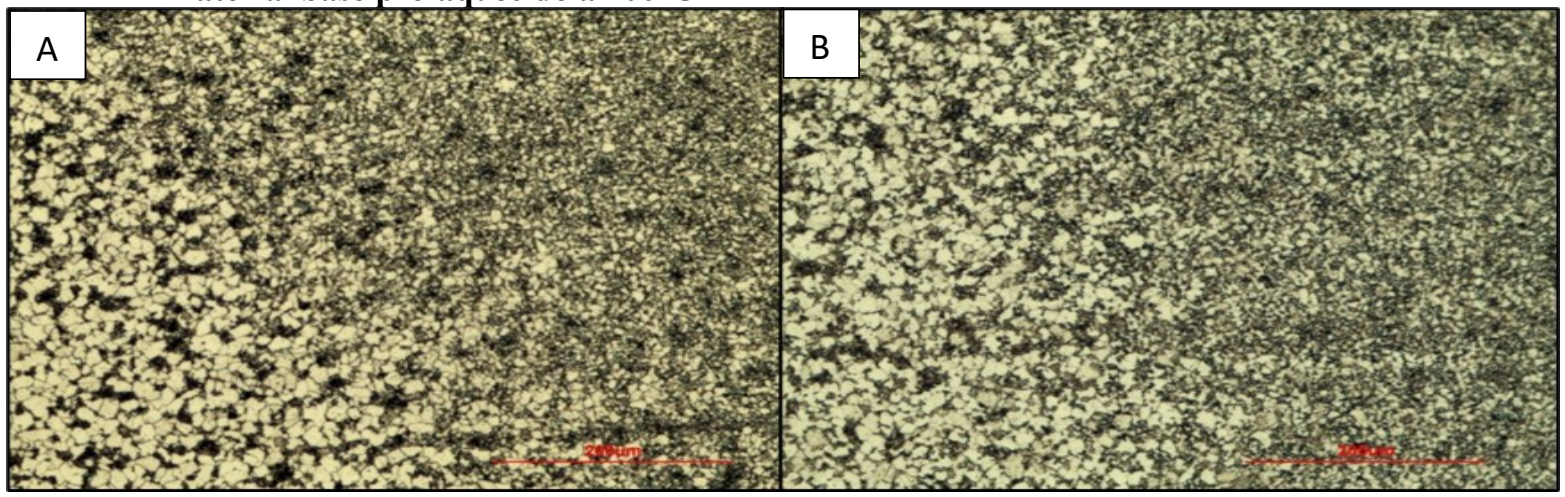

Fonte: os autores (2021)

Observa-se, no entanto, que a amostra com pré-aquecimento à $200^{\circ} \mathrm{C}$ apresentou grãos ligeiramente mais crescidos, provavelmente devido ao resfriamento mais lento, visto o préaquecimento aplicado. Esse crescimento de grãos, favoreceu à ocorrência de uma microestrutura mais uniforme da região da Zona Térmicamente Afetada com o Metal de base, como pode ser observado em maior aumento (200x) na figura 9.

Figura 9 - Metal base e ZTA ataque Nital 3\% em aumento 200x. (A) Material base não pré-aquecido e (B) Material base pré-aquecido à $200^{\circ} \mathrm{C}$

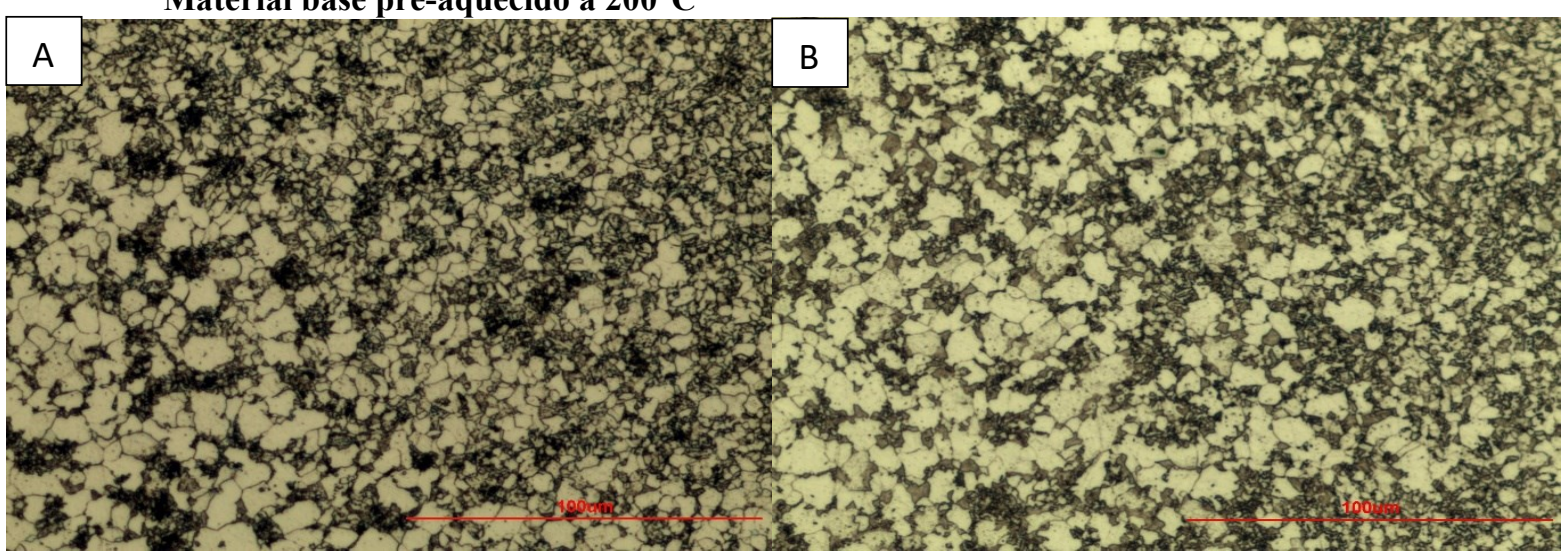

Fonte: os autores (2021)

Na Figura 10, observa-se a região de transição entre a ZTA e a região do metal de solda, em que se observa a formação de microestruturas mais uniformes e refinadas entre essas regiões na amostra que foi pré-aquecida a $200^{\circ} \mathrm{C}$. Observou-se um maior refinamento das lamelas de perlita e da ferrita na microestrutura do material, na amostra que ocorreu aplicando-se o tratamento de pré-aquecimento à $200^{\circ} \mathrm{C}$ (Figura 9B), comparado ao material sem tratamento de pré-aquecimento (Figura 9A). Verifica-se ainda, na zona fundida, também um maior refinamento na microestrutura, verificando-se a formação de bainita mais refinada na amostra com pré-aquecimento. Dessa forma, verifica-se que, devido ao pré-aquecimento, a taxa de resfriamento mais lenta favoreceu ao maior refinamento na microestrutura da região de solda, refinando-se e uniformizando-se as microestruturas da ZTA e da região de solda, tornando-a assim menos frágil e mais resistente. 


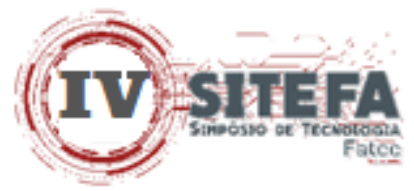

Figura 10- ZTA e metal de solda ataque Nital 3\% em aumento de 50x. (A) Material base não pré-aquecido e (B) Material base pré-aquecido à $200^{\circ} \mathrm{C}$

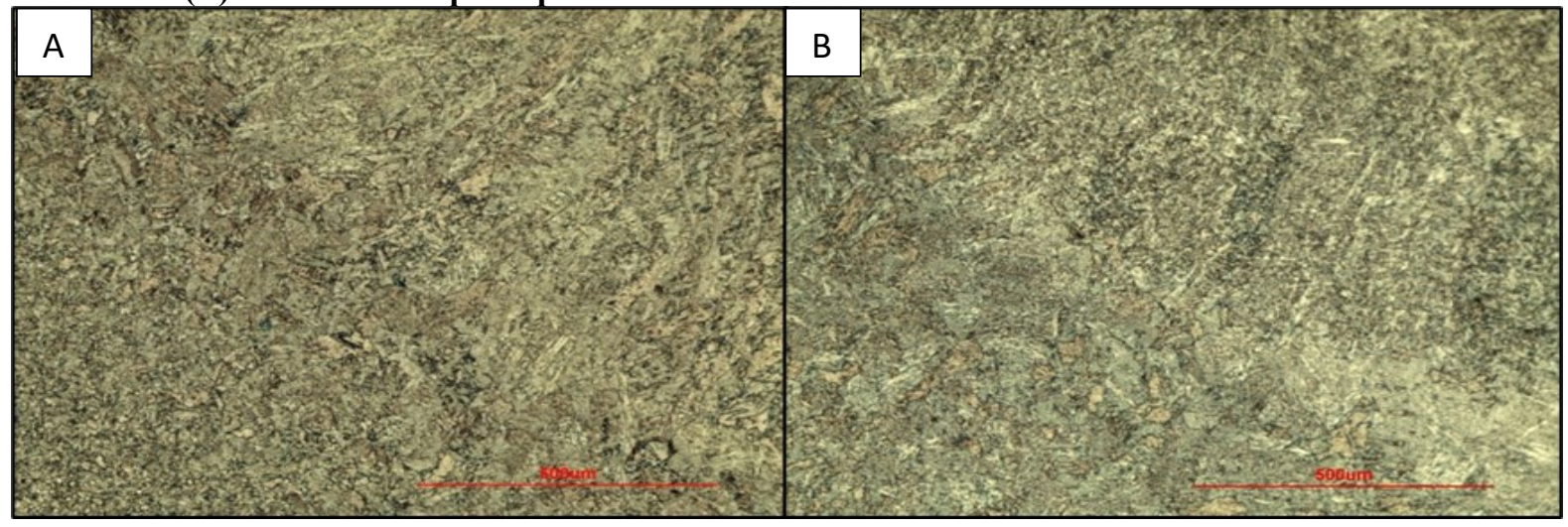

Fonte: os autores (2021)

As Figuras 11A e 11B referem-se ao metal de solda (MS) não pré-aquecido e préaquecido a $200^{\circ} \mathrm{C}$, respectivamente. Nota-se a formação de textura bruta de solidificação em ambos os materiais com e sem o pré-aquecimento. Pode-se observar que o material não préaquecido (Figura 11A) apresenta microestrutura mais grosseira com formação predominante de bainita irregular quando comparado ao material pré-aquecido, onde também se observa a presença de bainita, mas com aspecto mais refinado. Novamente a menor taxa de resfriamento, favoreceu a formação de uma microestrutura bainítica mais refinada, que melhora as características mecânicas do material. De acordo com Azevedo, Domingos e Alvarenga (2014), a irregularidade nessa distribuição confere ao material perda de ductilidade e aumento de fragilidade.

Figura 11 - Metal de solda ataque Nital 3\% Aumento 200x (A) não pré-aquecido e (B) pré-aquecido à $200^{\circ} \mathrm{C}$

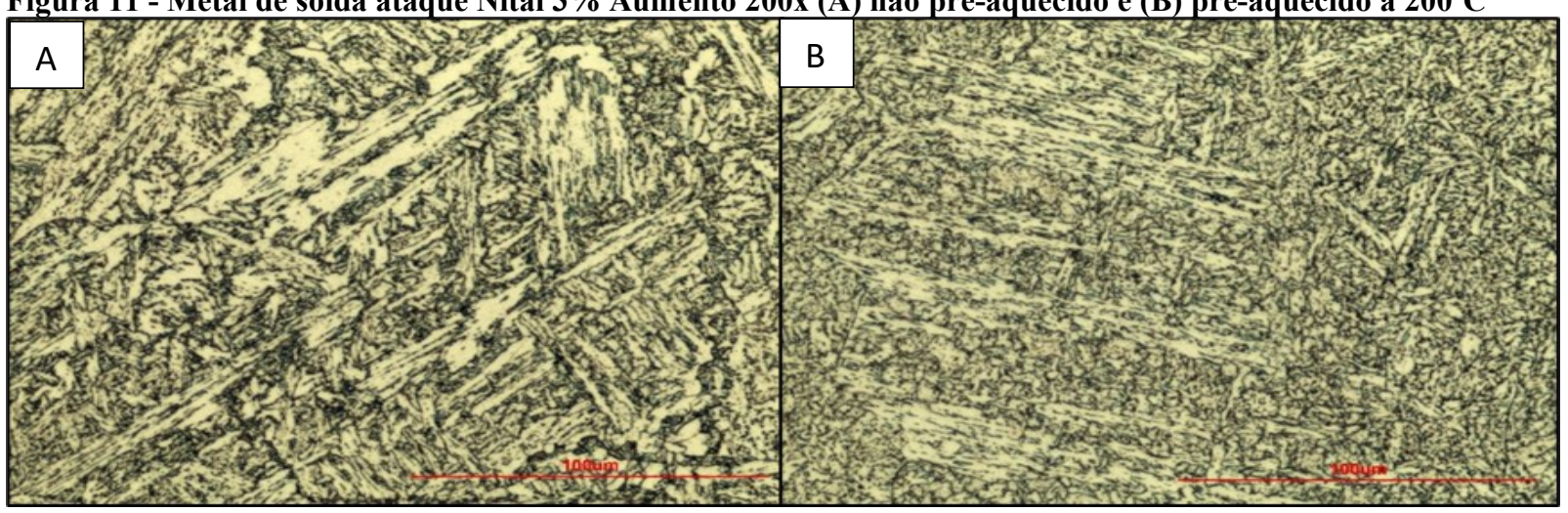

Fonte: os autores (2021)

\subsection{Ensaios de Microdureza (Vickers)}

A Figura 12 apresenta os resultados obtidos no ensaio de Microdureza Vickers no corpo de prova soldado a temperatura ambiente $\left(+/-30^{\circ} \mathrm{C}\right)$, ou seja, sem pré-aquecimento. Os resultados mostram uma dureza máxima de 202,5 HV no metal de base (MB), de 200,1 HV na ZTA e de 241,9 HV no metal de solda (MS). 


\section{(IV) SIIEFA}

Figura 12 - Perfil de dureza da junta soldada sem pré-aquecimento (valores em HV)

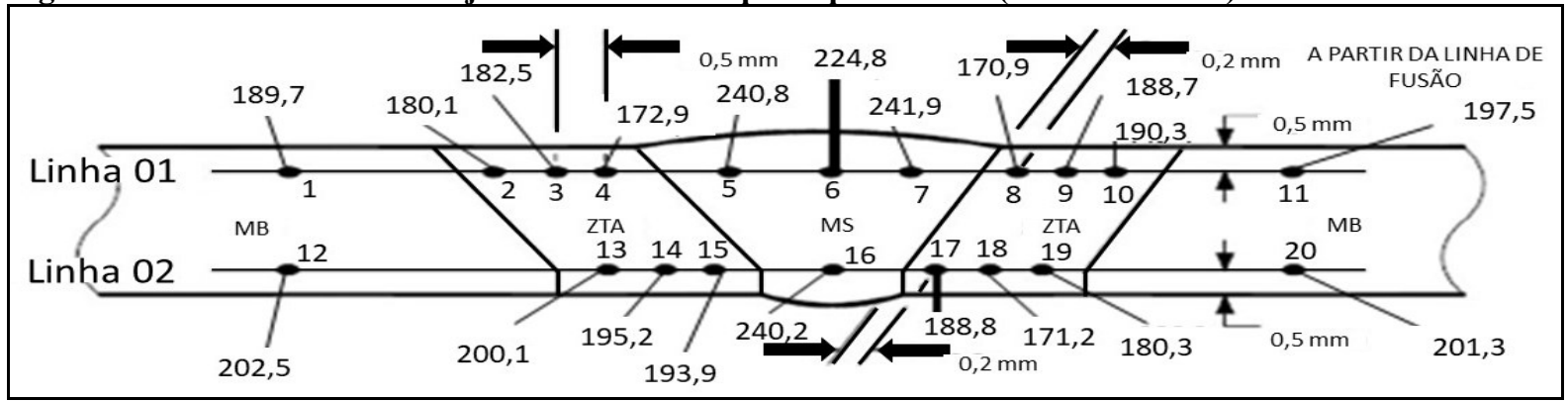

Fonte: os autores (2021)

A figura 13 apresenta os resultados de Microdureza Vickers obtidos no corpo de prova com pré-aquecimento de $200^{\circ} \mathrm{C}$. No metal de base (MB) obtive-se uma dureza máxima de 209,3 HV, de 258,9 HV na ZTA e de 254,0 HV no metal de solda (MS).

Figura 13 - Perfil de dureza da junta soldada com pré-aquecimento de $200^{\circ} \mathrm{C}$ (valores em HV)

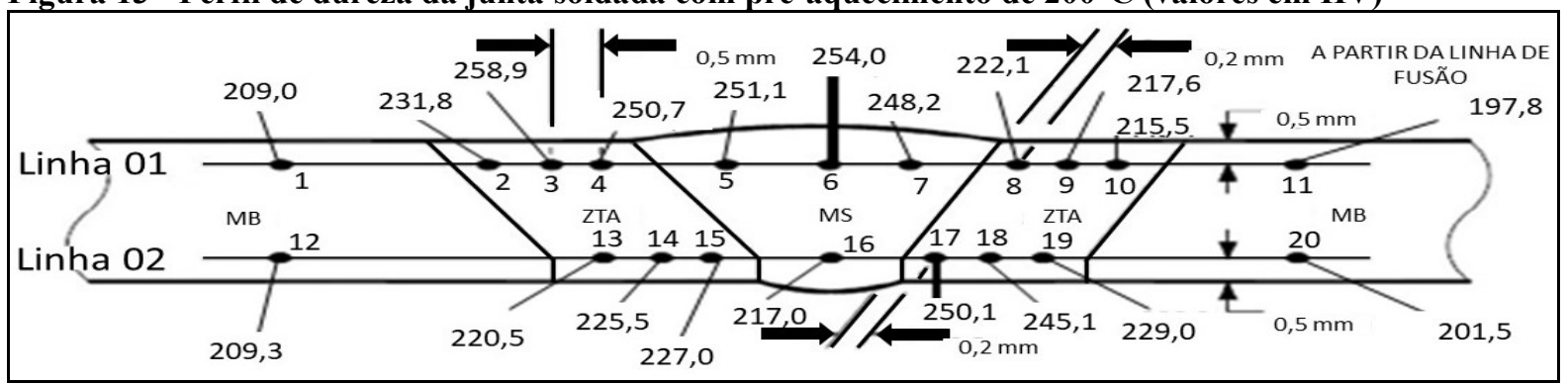

Fonte: os autores (2021)

Observando as Figuras 12 e 13, que mostram as medidas de microdureza, pode-se observar que houve um ligeiro aumento de dureza no perfil geral das medidas, na amostra que sofreu o pré-aquecimento à $200^{\circ} \mathrm{C}$, devido ao tempo de resfriamento mais lento tornando também o perfil das durezas mais uniforme ao longo das regiões de Solda, ZTA e metal base.

Comparando os resultados expostos na Figura 14, pode-se observar que com a aplicação de pré-aquecimento à $200^{\circ} \mathrm{C}(\mathrm{CP} 2)$ houve um aumento de tempo de resfriamento, por consequência um ligeiro aumento na dureza, mas mantendo dentro dos limites aceitáveis para o aço ASTM A335 P11, comparado ao tratamento sem pré-aquecimento (CP 1).

Figura 14 - Perfil de Microdureza Vickers nos corpos de prova das juntas soldadas pré-aquecido $200^{\circ} \mathrm{C}$ e não pré-aquecido

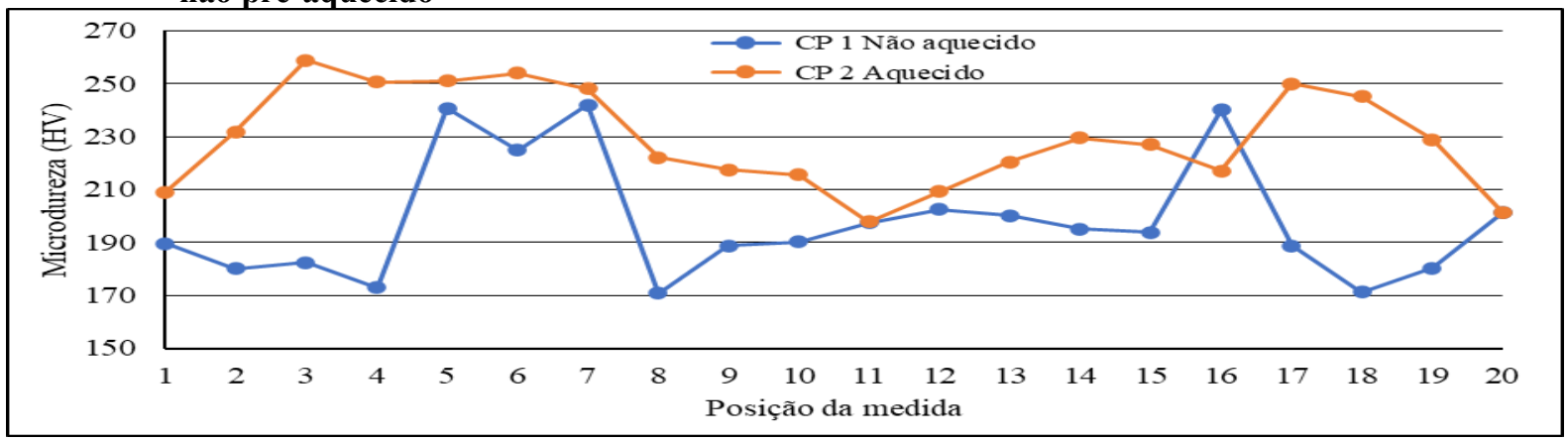

Fonte: os autores (2021) 


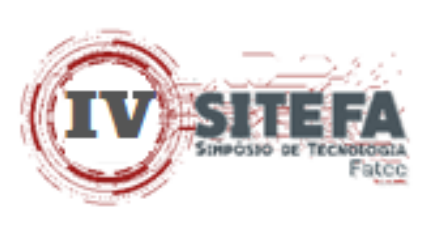

\subsection{Ensaios de Tração}

Pode-se observar na Figura 15, as curvas de Tensão x Deformação das amostras, um ligeiro aumento de resistência à tração na amostra com a aplicação da temperatura de préaquecimento (CP 2), comparado à amostra soldada sem pré-aquecimento (CP 1). A ligeira alteração na microestrutura contribuiu na diferença de limite de escoamento e \% alongamento.

Figura 15 - Ensaio de tração CPs das juntas sem pré-aquecimento $(\mathrm{CP1})$ e pré-aquecido à $200^{\circ} \mathrm{C}(\mathrm{CP2})$

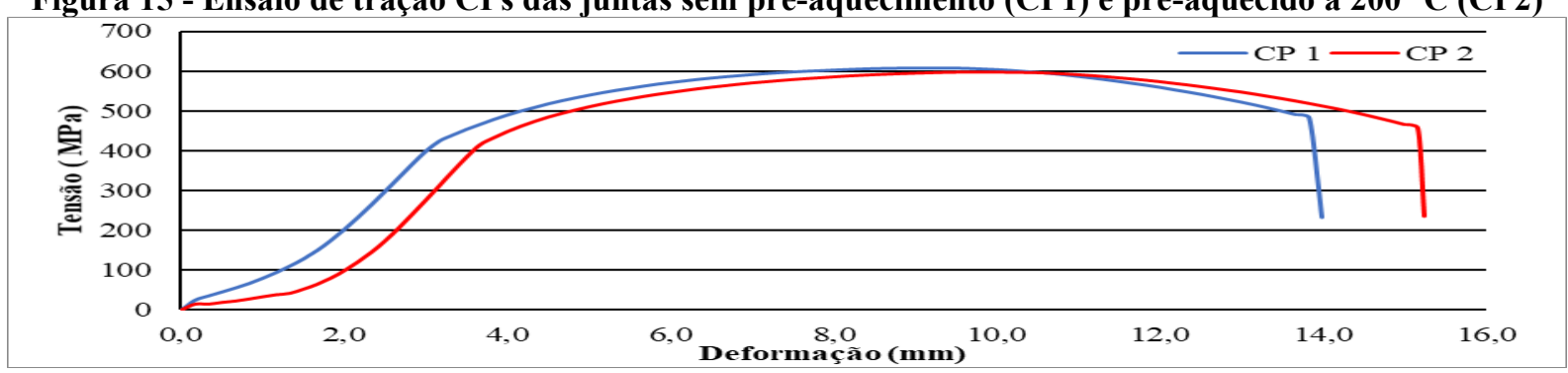

Fonte: os autores (2021)

Tendo em vista que o limite mínimo especificado de resistência a tração para aço ASTM A335 P11 é de $415 \mathrm{MPa}$, pode-se notar que em ambos os casos, obteve-se valores sensivelmente superiores. Comparativamente, observou-se um comportamento mais dúctil da amostra que foi pré-aquecida à $200^{\circ} \mathrm{C}$, apresentando maior deformação à ruptura.

\section{CONCLUSÃO}

Através dos testes realizados pode-se concluir que houve alterações discretas, porém significativas nas microestruturas da zona termicamente afetada e da zona fundida tanto para a junta do material ASTM A335 P11 não pré-aquecido quanto para a junta pré-aquecida à temperatura de $200^{\circ} \mathrm{C}$, visto a melhor uniformização microestrutural, que refletiu na maior uniformidade no perfil de durezas e na maior ductilidade no ensaio de tração observadas.

Conclui-se ainda que houve um aumento de dureza nas amostras com pré-aquecimento à $200^{\circ} \mathrm{C}$, pois acabou por influenciar no tempo de resfriamento, tornando-o mais lento, favorecendo a uniformização da microestrutura e crescimento de grãos, aumentando o limite de resistência à tração e o aumento da \%alongamento da junta soldada.

Por fim conclui-se que o pré-aquecimento à $200^{\circ} \mathrm{C}$ influi favoravelmente na microestrutura, na uniformização do perfil dureza e na ductilidade e resistência à tração na junta soldada do metal base ASTM A335 P11.

\section{REFERÊNCIAS}

AMERICAN SOCIETY FOR TESTING AND MATERIALS. ASTM. The history of ASTM international. West Conshohocken: ASTM-International, 2016. Disponível em: https://www.astm.org/ABOUT/history_book.html. Acesso em: 08 fev. 2021.

A335/A335M: standard specification for seamless ferritic alloy-steel pipe for hightemperature service. West Conshohocken: ASTM-International, 2015. 


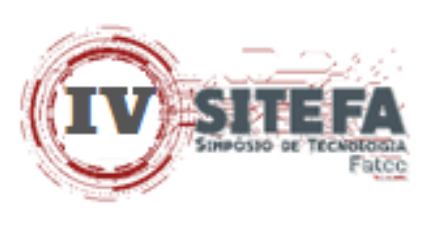

AMERICAN SOCIETY OF MECHANICAL ENGINEERS. ASME. Power piping. code for pressure piping, B31.1. 1 ed. Nova Iorque: ASME, 2016.

BOSQUETTI, P. et al., Produção da junta soldada do aço ASTM A335 P11 para tubulação de vapor em caldeiras: caracterização por análise microestrutural e microdureza. Revista Academus, Sertãozinho, 2015, v. 3, n. 1, p. 1-8. Disponível em: https://www.revistaacademus.com.br/revista/index.php/revistaacademus/article/view/19/24. Acesso em: 08 fev. 2021.

CAMPBEL, R. D.; La COURSIERE, E. J. A guide to the use of tungsten electrodes for GTA welding. Welding Journal, Miami, v. 74, n. 1, p. 39-45, 1995.

CIRINO, L. M. Estudos dos efeitos da polaridade na soldagem com corrente contínua e alternada pelos processos TIG e MIG/MAG. 2009. Dissertação (Mestrado em Engenharia Mecânica) - Universidade Federal de Santa Catarina, Florianópolis, 2009.

FONSECA, A. S. Soldagem TIG. Varginha: SENAI Centro de Formação Profissional "Aloysio Ribeiro de Almeida", 2004.

FORTES, C. Apostila de Metalurgia da Soldagem. Contagem: Esab, 2005.

GASPAR, N. J. Potencial uso do passe de revenimento no reparo de soldas: avaliação via mapeamento de durezas. 2013. Dissertação (Mestrado Profissionalizante em Engenharia Mecânica) - Universidade Santa Cecília, Santos, 2013.

GIMENES JUNIOR, L. Tratamento térmico em juntas soldadas. 1997. Disponível em: https://infosolda.com.br/wp-content/uploads/Downloads/Artigos/metal/tratamento-termicoem-juntas-soldadas.pdf. Acesso em: 08 fev. 2021.

MACHADO, I. G. Soldagem e técnicas conexas: processos. Porto Alegre, RS: Ed. do Autor, 1996.

MARQUES, P. V.; MODENESI, P. J.; BRACARENSE, A. Q. Soldagem: fundamento e tecnologia. 3. ed. Belo Horizonte: UFMG, 2011.

OKUMURA, T.; TANIGUCHI, C. Engenharia de soldagem e aplicações, Rio de Janeiro: Livros Técnicos e Científicos Editora S.A, 1982.

PEREZ, F. R. C. A influência da temperatura de pré-aquecimento na microestrutura e propriedades mecânicas na soldagem MIG/MAG robotizada de aços SAE $8620 \mathrm{com}$ ABNT LN28. 2007. Dissertação (Mestrado em Engenharia Mecânica) - Faculdade de Engenharia: UNESP, Bauru, 2007.

ROSALINO, A. L.; SFALSIN, L. M. J.; SIQUEIRA, T. R. Análise da influência do préaquecimento em uma junta soldada com eletrodo revestido - aço SAE1045. FAACZ, Aracruz, ES, 2014. 
TELLES, P. C. S. Tubulações industriais materiais, projetos, montagem.10 ${ }^{a}$ ed. Rio de Janeiro, UFRJ, 2001.

TUBOS ABC. Aplicações dos tubos de aço liga ASTM A335. 2019. Disponível em: https://www.tubosabc.com.br/produtos/tubos/tubos-de-conducao-aco-liga/tubo-de-aco-ligaastm-a335/. Acesso em: 08 fev. 2021.

WAINER, E.; BRANDI, S. D.; MELLO, F. D. H. de. Soldagem processos e metalurgia. 8 Reimpressão. São Paulo: Edgard Blücher LTDA, 2011.

ZAMPIERI JÚNIOR, C. R. Determinação da tenacidade a fratura da região da solda de um tubo de aço ferrítico ASTM A335 Gr. P22 através do deslocamento da abertura da ponta da trinca (CTOD). 2014. Dissertação (Mestrado em Ciência e Engenharia de Materiais) - Universidade de São Paulo, São Carlos, 2014. 